\title{
Development of Land Engineering Discipline
}

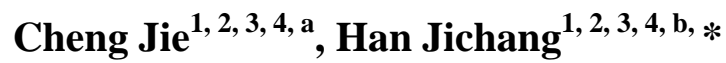 \\ ${ }^{1}$ Institute of Land Engineering and Technology, Shaanxi Provincial Land Engineering \\ Construction Group Co., Ltd., Xi'an 710075, China; \\ ${ }^{2}$ Shaanxi Province Land Engineering Construction Group, Xi'an 710075, China; \\ ${ }^{3}$ Key Laboratory of Degraded and Unused Land Consolidation Engineering, the Ministry of Land \\ and Resources of China, Xi'an 710075, China; \\ ${ }^{4}$ Shaanxi Provincial Land Consolidation Engineering Technology Research Center, Xi'an 710075, \\ China. \\ a568761241@qq.com, ${ }^{b}$ 2100653101@qq.com \\ *corresponding author
}

Keywords: land resource; present situation; land engineering discipline

Abstract: Land is the foundation of human being. Based on the background of land problems, the proposed land engineering discipline, and the construction of the subject have been proposed to arouse wide attention from all sectors of society on land engineering, to further accelerate the land engineering construction work, and promote land engineering industry development.

\section{Introduction}

Land is a long history, which people have kept on learning, using and developing since the human existence, and land is as human as air and water are indispensable. However, the knowledge about the land is scattered in all fields, so far no independent first-level subject has been formed. With the further increase in the contradiction between human and land supply and demand, people are increasingly realizing the technical problems of land remediation and the ecology of land resources Therefore, the subject of "land engineering" is put forward. At present, although the discipline has been basically established, it is not mature enough. In this paper, the course of the construction of land engineering is briefly introduced in order to arouse the community colleagues Extensive attention to the discipline of land engineering, understand the construction dynamics, so that more experts and scholars, front-line technicians to join the army of land engineering disciplines to ensure the sustainable use of land resources.

\section{Land Engineering Discipline Proposed}

Land is the foundation of humankind. Our country attaches great importance to the quantity and quality of land. It has always cherished, used land rationally and effectively protected the cultivated land as our country's basic national policy. In 2015, General Secretary Xi Jinping pointed out that protecting cultivated land should be done like protecting cultural relics, or even like protecting giant panda, while unswervingly adhere to the most stringent arable land protection system and 
land-saving system. Nevertheless, in the process of rapid human development, the land is still greatly damaged. According to statistics, the area of land degradation is as high as 539.2 million hectares, accounting for $56.2 \%$ of the total land area of China. Among them, the area of soil and water loss is 180 million hectares, the degraded land area is 33.4 million hectares, the soil salinization area is 99.13 million hectares, the grassland degradation area is 3 billion hectares, and the soil pollution area is 200 million hectares. Therefore, in order to study land issues, explore and solve the technical problems of land engineering and ensure food security and farmland security, in 2013, Han Ji-Chang first proposed "land engineering" based on years of practical experience and scientific research experience in land renovation projects, that is, the unused land into usable land or the use of the land for efficient use of the dynamic coordination of the harmonious development of human relations process is a survey of land resources, Evaluation, planning, development, remediation, utilization and protection of various projects in a comprehensive discipline. Through the non-agricultural land into agricultural land projects, land for construction projects, decontaminated land improvement projects, low standards of land improvement project four projects covering the use of agricultural land, construction land, decontaminated land and low standards of land improvement Through engineering measures to improve the effective land area, increase land utilization, increase land productivity, protect social land and food security, and effectively solve the contradiction between supply and demand of land. Land engineering is not only a project construction, but also a complex discipline system integrating scientific theory research, engineering technology development and engineering practice (Han, 2013).

From a national perspective, the ability of land use to occupy, utilize and manage land resources determines the historical process of a country. From a social perspective, land engineering is an effective measure to increase land resources and solve conflicts between people and land. From an economic point of view, land engineering is an inevitable choice to ensure that arable land balances up and complement each other and promote social and economic development. From the perspective of ecological environment, land engineering is a necessary means to improve the ecological environment and improve people's living standards.

\section{Promote the Process of Land Engineering Disciplines}

\subsection{Proposed mark of land engineering discipline}

In March 2013, Introduction to Land Engineering was published, which represented formal project of land engineering. For the first time, this book proposed "Land Engineering Subject", initially defining the scope of land engineering research, and elaborating the disciplinary system, disciplines basic, research methods specifically, which different from the previous "Land Science." The publication of Introduction to Land Engineering laid the foundation for the development of land engineering discipline and opened the door to the construction of land engineering discipline.

\subsection{Construction started of land engineering discipline}

In April 2013, the Key Laboratory of Land Degradation and Unutilized Land Renovation Project of Ministry of Land and Resources and Land Special Committee of China Natural Resources Society convened the "Land Engineering High-level Symposium" in Beijing. Academician of Chinese Academy of Engineering, Ministry of Land and Resources, Ministry of Water Resources More than 20 academician experts attended the seminar. The symposium mainly discussed the objectives and tasks of land remediation engineering practice, land engineering discipline construction and engineering technology innovation in China, clarified the connotation and orientation of discipline construction, and put forward the foreword questions of land science 
research and field. Participants agreed that the development of land engineering disciplines of great significance, the urgent need to launch land remediation business "new engine", with reference to the organization of water conservancy and mineral engineering disciplines of land engineering disciplines to explore the establishment of land engineering disciplines, the formation of land engineering technology System, while improving the relevant laws and regulations in order to promote scientific and technological innovation in land, promote the sustainable use of land resources(Chinese Natural Resources Society,2013).

In July of the same year, the Department of Science, Technology and International Cooperation of the Ministry of Land and Resources hosted the Symposium on Exchanges of Science and Technology Achievements and Land Engineering in China on Land Reclamation and Reclamation and Development in Xi'an. Experts from Chinese Academy of Sciences, Academy of Engineering, universities and research institutes, more than 240 people, including the Science and Technology Department of the competent provincial department of land and resources, heads of provincial-level land reclamation centers and chief technical officers, heads of national science and technology projects in the field of land and key laboratories in the Ministry of Land Affairs, attended the seminar. The participating academicians and experts unanimously approved and supported the construction of land engineering discipline and played an active role in continuing to promote scientific research, technological innovation and transformation of achievements in land engineering (Western Network, 2013).

\subsection{The first land engineering college established}

In September 2015, Chang'an University and Shaanxi Provincial Land Engineering Construction Group co-founded the first land engineering institute in China and formed three levels of land information and land resources construction initial stage, land remediation project, land use and protection project Discipline system. The establishment of the college is a milestone in the construction of the discipline of land engineering and is also a new direction for the scientific and technological personnel to support the reform and development of the land undertaking. At present, the Institute of Land Engineering has begun to enroll students to carry out land engineering technical problems, while cultivating land engineering professionals.

\subsection{Land engineering discipline developed rapidly}

The development of land engineering has continuously injected new strength, and began to enter a period of rapid development.

In April 2016, Shaanxi Provincial Bureau of Land and Resources and Shaanxi Provincial Bureau of Foreign Experts Affairs hosted the "Sino-US Symposium on International Cooperation in Land Engineering" in Xi'an and experts and scholars from 6 countries including China, the United States, Russia and Mongolia. The conference held discussions on issues such as agricultural land development and reorganization, industrial pollution land remediation methods and technologies. In response to the current global issues such as soil defacement, inefficient utilization and lack of scientific and technological support for land remediation projects, the General Assembly approved the "Proposal of Establishing the International Society of Land Engineering" and the "Xi'an Declaration on Land Engineering and Land Ecological Development" , For the first time issued a global initiative "to create land engineering disciplines, training of land engineering talent" initiative, Sun Jiu-Lin academician of Chinese Academy of Engineering said that the land engineering discipline is particularly necessary, but also particularly urgent, and only the construction of land engineering disciplines to form a complete discipline System in order to fundamentally solve the problems of the existence of land and ensure the sustainable and efficient 
use of land resources.

In the same period, Han Ji-Chang researcher summed up the core research tasks and research contents of land engineering based on years of experience in land engineering research, that is, soil organic reconstruction, which through the study of a certain depth of soil, with replacement, compounding and reconstruction and other technical means, to provide the necessary conditions for carrying life. Its research goal is to build a life system, and the object of service for the organic life body, the scope of the study is mainly defined in the first layer from the surface to the diving layer, vertical span from a few centimeters to hundreds of meters. Soil organic reconstruction is the core of land engineering, and is the foundation of land engineering discipline as an independent discipline (Shaanxi Daily, 2016).

In September 2016, Massachusetts Institute of Technology Global Industry Alliance (MIT-ILP) and Shaanxi Provincial Land Engineering Construction Group hosted the MIT Global Innovation Forum --- Emerging International Studies of Big Data and Land Engineering in Xi'an More than 50 Chinese and foreign experts and academicians, including academicians from the Chinese Academy of Engineering, Fu Bo-Jie, academicians from the Chinese Academy of Sciences, Tang Zhong-Li and Li Pei-Cheng, attended the conference. The conference focused on the issues of urban data and land engineering and a series of academic issues were discussed, the meeting effectively promoted the integration of big data and land science and technology development, to promote the development of land engineering disciplines, and promote the sustainable development of land ecology and land engineering played an important role (Western network, 2016).

December 2016 Ministry of Land and Resources Key Laboratory of Degradation and Unutilized Land Renovation Project hosted a Symposium of Key Laboratory of Science and Technology Innovation and Land Engineering of Ministry of Land and Resources, academicians of Chinese Academy of Engineering Tang Zhongli, Sun Jiu-Lin, academician Shan Lun, Resources Department, Peking University, Xi'an Jiaotong University, Shaanxi Normal University and other relevant academicians for the first time jointly advocated "establishment of undergraduate land engineering." Han Ling, Science and Technology Department of Chang'an University, made a report on the setting of professional land engineering. All the experts and scholars gave advice and suggestions on land science and technology innovation and subject construction, which promoted the sound and rapid development of land engineering.

\subsection{Land remediation project included in the national education sequence}

In March 2017, the Ministry of Education issued the Notice on Publishing the Results of the Record and Examination and Approval of Undergraduate Majoring in Colleges and Universities for 2016 (Teach high [2017] No. 2), stipulating that the "Land Renovation Project" is a newly approved undergraduate major, Respectively, Chang'an University, China University of Geosciences (Beijing) set up undergraduate engineering. It marked that land remediation project was formally incorporated into the undergraduate sequence of national education and the construction of land engineering discipline entered a new historical stage.

\subsection{Land engineering branch out of the country}

In April 2017, the International Association of Urban Management (ICMA), the Institute of Agricultural Resources and Agricultural Zoning of the Chinese Academy of Agricultural Sciences and the Land Engineering Construction Group of Shaanxi Province hosted and held the (2nd) International Cooperation Academic Exchange Conference on Land Engineering between China and the United States. More than 500 domestic experts from the United States, Britain and other countries as well as Chinese Academy of Sciences and the Chinese Academy of Agricultural 
Sciences held a total of more than 500 exchanges and discussions on scientific and technological innovation in land engineering and the ecological construction of land engineering. The conference set up the secretariat of the Sino-American joint conference on academic cooperation in the field of land engineering and the committee of experts for the construction of land engineering disciplines, which is conducive to promoting exchanges and mutual learning among professionals in land engineering and further promoting and promoting the construction of land engineering disciplines and cultivating land engineering expertise Talent has an important role. Land Engineering is steadily fast and sound.

In December 2017, the 3rd Sino-US Symposium on Land Engineering International Cooperation held by ICMA and Shaanxi Provincial Land Construction Group held in Pittsburgh. This conference has built a platform for domestic and foreign experts to exchange experiences and technologies in international governance of contaminated land and restoration of land ecology. The conference is of great significance to expanding the Group's international influence and promoting the development of land engineering disciplines and the prosperity of land engineering.

\subsection{Land engineering monographs}

In 2016, he published monographs "Land Engineering Principles", "Foundation of Land Engineering" and "Land Engineering Practice". Among them, "Principles of Land Engineering" expounds the theoretical basis of the research on supporting land engineering; "Foundation of Land Engineering" introduces the core and depth of the study; "Land Engineering Practice" points out the technical routes and methods for various types of land engineering research, which with the Introduction to Land Engineering to Promote the Construction of Discipline System. At present, many textbooks for land engineering are gradually taking shape.

\section{Conclusion}

Outstanding land issues urgently need a scientific and rational theoretical discipline for guiding engineering practice, therefore, the construction of land engineering discipline without delay. In a short period of three years, significant progress has been made in the construction of the discipline of land engineering. The first land engineering college was established. Four major monographs were published and received recognition and support from all walks of life. However, land researchers are still required to make a large number of jobs. Here are some suggestions:

First, the construction of land engineering discipline should be further based on the basic elements of an independent discipline, to improve and enrich the content of soil organic reconstruction. The second is to seize the main contradictions of the land, to further sort out the scope of the land engineering research, and to further improve the discipline system of the land engineering discipline. The third is to strengthen the research work of land engineering research projects and obtain major national and world-level research results. Fourth, continue to strengthen the social influence of the construction of land engineering disciplines, especially in the influence of universities, called for major colleges and universities to create additional land engineering undergraduate. Fifth, it has aroused the attention of the corresponding government departments to the land industry, especially the current land issue, and strengthened the importance of the Land Engineering Branch in solving the land issue. "The ultimate goal of land engineering is ecological civilization. Only clean land can build (grow) healthy plants and living things, and the earth that carries everything can be more ecological and civilized." (Western Network-Shaanxi News Network, 2015) We may the land engineering discipline become a subject as soon as possible. 


\section{References}

[1] Han. J, C. Introduction to Land Engineering. Science Press .2013.

[2] High-level Symposium on Land Engineering Held Successfully in Beijing.Chinese Natural Resources Society .2013-5-15.

[3] National Land Reclamation and Development Science and Technology Innovation Achievements Exchange Conference Held in Shaanxi, Western Network. 2013-7-31.

[4] Soil organic reconstruction is the core of the quality of land engineering. Shaanxi Daily .2016-4-21

[5] Chinese and American academicians gathered in Xi'an big data to promote the construction of new disciplines of land engineering. Western network. 2016-9-20.

[6] The First Sino-American Symposium on International Cooperation in Land Engineering was Held in Xi'an.Western Network-Shaanxi News Network .2015-4-18. 